\title{
PENGARUH GAME ONLINE TERHADAP KETAATAN BERIBADAH MAHASISWA DI JURUSAN PENDIDIKAN AGAMA ISLAM UNIVERSITAS MUHAMMADIYAH MALANG
}

\author{
Abdul Haris, Daniar Chandra Anggraini, Dina Mardiana \\ Program Studi Pendidikan Agama Islam, Universitas Muhammadiyah Malang \\ J1. Raya Tlogomas No. 246 Kota Malang, Jawa Timur \\ Email: haris@umm.ac.id
}

\begin{abstract}
This study aims to determine the intensity of students in the Department of Islamic Education, University of Muhammadiyah Malang, especially students of 2017 and 2018 class in playing online games, and the effect on their religious observance. This study uses a quantitative approach with a sample of 52 students. The research data were collected using a questionnaire and analyzed using the correlation analysis product moment. The results showed that the majority of students played intensely online games. However, their intensity of playing online games did not have a significant effect on their religious observance. The results of the analysis with the product-moment indicates $0.206<0.279$ where $r_{\text {count }}$ is lower than $r_{\text {table. }}$.
\end{abstract}

\section{Keywords: Online Games, Religious Observance}

\begin{abstract}
Abstrak
Penelitian ini bertujuan untuk mengetahui intensitas mahasiswa di Jurusan Pendidikan Islam Universitas Muhammadiyah Malang, khususnya pada mahasiswa angkatan 2017 dan 2018 dalam bermain game online, dan pengaruhnya terhadap ketaatan beribadah mereka. Penelitian ini menggunakan pendekatan kuantitatif dengan sample sebanyak 52 mahasiwa. Data penelitian dikumpulkan dengan menggunakan kuesioner dan di analisis dengan menggunakan analisis korelasi product moment. Hasil penelitian menunjukkan mayoritas mahasiswa intens bermain game online, namun demikian intensitas mereka bermain game online tidak memiliki pengaruh yang signifikan terhadap ketaatan beribadah mereka. Hasil analisis dengan product moment menunjukkan 0,206 $<0,279$ di mana $r_{\text {hitung }}$ lebih rendah dari $r_{\text {tabel. }}$
\end{abstract}

\section{Kata Kunci: Game Online, Ketaatan Beribadah}




\section{PENDAHULUAN}

Saat ini perkembangan teknologi menglami kemajuan dengan sangat cepat. Hal ini dikarenakan, dalam segala aspek kehidupan, manusia membutuhkan teknologi yang cepat dan mudah digunakan. Kemajuan teknologi yang ada saat ini, tidak dapat dipisahkan dari segala kegiatan dalam kehidupan manusia sehari-hari. Salah satu perkembangan teknologi yang dibutuhkan manusia saat ini adalah pada bidang informasi dan komunikasi. Pada bidang ini, teknologi yang mengalami perkembangan pesat adalah internet. Dengan adanya internet, komunikasi antar satu orang dengan yang lain semakin mudah baik dalam jarak dekat maupun dalam jarak jauh.

Internet merupakan singkatan dari Interconnection Networking. Internet adalah suatu jaringan komunikasi global yang dapat menghubungkan miliaran jaringan dengan komputer secara teruji, karena di dalam jaringan ini menggunakan sistem standar global transmission control protocol/internet protocol (TCP/IP). Setiap komputer yang terhubung dengan jaringan ini, maka akan memiliki identitas unik yang disebut dengan Alamat IP atau Internet Protocol Address. Alamat IP ini berbentuk kombinasi angka untuk menunjukkan komputer tersebut terhubung dalam suatu jaringan internet yang tersedia (https://www.it-jurnal.com/pengertianinternet/).

Perkembangan internet telah menghasilkan beberapa bentuk aplikasi online seperti Game online. Aplikasi ini merupakan jenis permainan komputer yang memanfaatkan jaringan yang ada di komputer

(http://id.wikipedia.org/wiki/Permainan daring), Namun seiring berjalannya waktu, game online kini tidak hanya tersedia di komputer atau laptop saja akan tetapi juga tersedia di smartphone, sehingga memungkinkan pengguna untuk lebih banyak menghabiskan waktunya untuk bermain game online.
Beberapa jenis genre game online dalam smartphone banyak ditawarkan oleh para pengembang, diantaranya adalah Massively Multiplayer Online Role Playing Game (MMORPG), Massively Multiplayer Online Real Time Strategy (MMORTS), Massively Multiplayer Online First Person Shooter (MMOFPS), dan Multiplayer Online Battle Arena (MOBA) (Ramadhani, 2013:142-143). Dari berbagai jenis genre game online tersebut, genre MOBA merupakan genre yang paling banyak diminati oleh masyarakat saat ini, terutama oleh generasi remaja. Game genre MOBA yang paling banyak diminati saat adalah game Mobile Legends yang sudah diunduh sebanyak 35 juta kali dengan total pemain harian di Indonesia mencapai 8 juta pemain, dan Player Unknown's Battlegrounds (PUBG) yang sudah diunduh sebanyak lebih dari 100 juta kali (https://kumparan.com/kumparantech/ di-indonesia-mobile-legends-dimainkan8-juta-pengguna-aktif/full.)

Game online saat ini sudah melanda kehidupan masyarakat terutama kalangan pelajar dan mahasiswa. Sebagian dari mereka sudah sampai pada tarap apa yang oleh Kimberly Young disebut sebagai obsessive computer game playing yakni obsesif dalam bermain permainan computer (Young, 2000: 477). Obsesi semacam ini pada akhirnya menjadikan mereka kecanduan terhadap game online.

Bermain game online memberikan dampak bagi perilaku pelaku dan pecandunya. Beberapa penelitian menunjukkan bahwa game online mobile legends memberikan dampak negative terhadap pemainnya seperti acuh terhadap lingkungan sosialnya, boros waktu dan ekonomi, namun di sisi lain memberikan wawasan teknologi, memperluas jaringan interaksi dengan dunia luar (Rani, et.al, 2018:6; Putri et.al, 2021: 1). Kecanduan game online berpengaruh terhadap kemampuan komunikasi interpersonal. Semakin tinggi kecanduan game online, semakin rendah komunikasi interpersonal 
yang dihasilkan (Yusuf, et.al., 2019: 71). Kecanduan game online berdampak pada aspek kesehatan, psikologis, akademik, social, dan ekonomi (Novrialdy, 2019: 148). Game online memberikan pengaruh terhadap motivasi belajar. Semakin sering bermain game online, semakin rendah motivasi belajar (Ondang, et.al., 2020: 1; Nisrinafatin, 2020: 115). Kecanduan game online memiliki hubungan dengan penyesuaian social remaja. Semakin tinggi kecanduan game online, semakin rendah kemampuan melakukan penyesuaian social (Utami, et.al. 2020: 17).

Meskipun game online dapat memberikan dampak positif bagi pelakunya, namun dari beberapa penelitian di atas jika hal itu dilakukan secara berlebihan maka dampak negatifnya justru yang lebih banyak termasuk dalam hal ini adalah intensitas dalam menjalankan ibadah kepada Tuhan. Darwis et.al. (2020: 232) dalam penelitiannya menyatakan bahwa di antara faktor yang menyebabkan kecanduan game online dimulai dari menjauh dari Tuhan, kurangnya aktifitas, jenuh di rumah, dan keinginan untuk mencoba-coba. Orang yang sudah kecanduan game online cenderung lupa waktu sehingga mengabaikan tugas dan kewajibannya termasuk tugas dan kewajiban agamanya. Banyak orang yang bermain game online lupa makan, belajar, dan bahkan lupa beribadah kepada Tuhan karena keasyikan bermain.

Beribadah kepada Tuhan adalah kewajiban setiap orang beragama. Dalam ajaran agama Islam, beribadah kepada Allah adalah tujuan diciptakannya manusia (Q.S. Al-Dzariyat 56: .....). Dengan demikian, ibadah dalam Islam merupakan tugas dan tanggung manusia yang harus dilakukan untuk mendapatkan kemaslahatan dan kebaikan dalam hidupnya (Sudarsono, 2018: 54). Ibadah dilakukan sebagai bentuk ketundukan kepada Allah guna membersihkan diri dan mendapatkan ridla Nya (Zulkifli, 2017:
1). Setiap orang Islam harus selalu menjalankan ibadah dengan baik dan tidak meninggalkannya kecuali karena ada alasan syar'i yang membolehkannya. Bermain game online seharusnya tidak menjadikan orang melupakan ibadah kepada Allah Swt.

Di kalangan mahasiswa jurusan Pendidikan Agama Islam Universitas Muhammadiyah Malang, bemain game online menjadi hal yang banyak dilakukan oleh mayoritas mahasiswa. Berdasarkan observasi yang peneliti lakukan, banyak dari mereka yang bermain game online hingga mengakhirkan waktu pelaksanaan sholat lima waktunya, terutama saat waktu sholat Ashar, Maghrib dan Isya'. Game online yang sering mereka mainkan adalah genre MOBA karena, permainan tersebut dapat dimainkan secara bersamasama.

Sebagai mahasiswa yang sedang mendalami pendidikan agama Islam sudah seharusnya mereka memiliki ketaatan beribadah yang baik kepada Allah sebab mereka lebih memahami ajaran-ajaran agama dibandingkan dengan yang lain. Aris (2010:76) dalam penelitiannya menemukan adanya pengaruh positif antara pemahaman agama terhadap pengamalan ibadah. Demikian pula penelitian Sari (2018: 68) menyimpulkan hal yang serupa. Artinya semakin tinggi pemahaman seseorang terhadap agamanya, maka akan semakin baik pengamalan ibadahnya.

Dengan semakin maraknya game online di kalangan mahasiswa jurusan pendidikan agama Islam fakultas agama Islam UMM, peneliti tertarik untuk mengetahui apakah ada pengaruh game online terhadap ketaatan beribadah mereka. Atas dasar itu, maka penelitian ini ditujukan untuk mengetahui intensitas mahasiswa jurusan Pendidikan Agama Islam Fakultas Agama Islam Universitas Muhammadiyah Malang dalam bermain game online, dan pengaruh game online terhadap ketaatan beribadah mereka. 


\section{Kajian Literatur}

Game online adalah permainan yang sering dimainkan oleh siapapun saat ini, baik dari kalangan anak-anak, remaja hingga dewasa. Game online merupakan permainan video yang dimainkan menggunakan jaringan komputer, menggunakan komputer pribadi atau konsol video game. Jaringan yang digunakan bersumber dari internet, baik menggunakan modem atau keras kabel terminal sebelum adanya modem (Surbakti, 2017:30). Game online merupakan game komputer yang dimainkan oleh multi pemain melalui internet. Dalam memainkan game online, ada dua perangkat yang wajib digunakan, yakni seperangkat komputer dengan spesifikasi yang memadai dan komputer terhubung dengan koneksi internet (Kustiawan dan Utomo, 2019: 6).

Game online merupakan permainan yang dapat diakses oleh banyak pemain, mesin-mesin yang digunakan oleh pemain dihubungkan oleh suatu jaringan yang tersedia Adamas, 2010: 1). Menurut Winn dan Fisher, multiplayer online game adalah bentuk pengembangan dari game yang dimainkan oleh satu orang dalam bagian yang besar, dengan menggunakan bentuk, metode dan konsep umum yang sama dengan game yang lain, hanya saja yang membedakan yaitu multiplayer game dapat dimainkan oleh banyak orang dalam waktu yang sama (Kustiawan dan Utomo, 2019: 6).

Berdasarkan beberapa pengertian yang sudah ada diatas, maka dapat disimpulkan game online adalah salah satu jenis permainan yang ada di komputer yang dimainkan menggunakan jaringan internet yang ada. Game online juga dapat dimainkan secara multiplayer, dalam waktu yang sama, dan juga dapat dilakukan dengan menggunakan komputer maupun handphone.

Terdapat beberapa jenis game online yang dapat dimainkan bersamasama, jenis-jenis tersebut adalah sebagai berikut:
1. Massively Multiplayer Online Role Playing Game (MMORPG). Permainan jenis ini didalamnya adalah memainkan peran tokohtokoh khayalan yang dilakukan bersama untuk membentuk cerita dalam permainan tersebut. Jenis permainan ini lebih mengarah kepada kolaborasi social daripada berkompetisi. Contoh game online dari jenis ini adalah Ragnarok Online, The Lord Of The Rings, Final Fantasy, dan lain sebagainya.

2. Massively Muktiplayer Real Time Strategy (MMORTS). Permainan jenis ini memiliki ciri khas yakni para pemainnya harus ahli dalam mengatur strategi permainan tersebut. Pada jenis ini, maka dibutuhkan kehebatan yang lebih dalam setiap pemain untuk mengatur strategi (Surbakti, 2017: 32). Karena jika tidak ahli dalam mengatur strategi, maka pemain tersebut akan mudah dikalahkan oleh lawan mainnya tersebut. Contoh game online dari jenis ini adalah Age of Empires, Star Wars, Warcraft, dan lain-lain.

3. Massively Multiplayer Online First Person Shooter (MMOFPS). Permainan jenis ini menggunakan sudut pandang orang pertama sehingga pemain seolah-olah berada dalam dunia permainan tersebut. Karakter pemain yang sedang dimainkan tersebut memiliki tingkat kemampuan yang berbeda-beda. Setting tempat yang digunakan dalam permainan jenis ini, kebanyakan dengan latar belakang peperangan dengan menggunakan senjata-senjata militer. Contoh permainannya adalah Call Of Duty (COD), Point Blank (PB), Counter Strike, dan lain-lain (Surbakti, 2017: 32)

Multiplayer Online Battle Arena (MOBA). Permainan dengan jenis ini menggunakan action real time yang 
merupakan turunan dari genre strategi. Dalam genre ini, pemain hanya dapat mengontrol satu karakter yang dipilih. Dengan tujuan untuk memenangkan permainan dengan cara menghancurkan semua bangunan inti dari tim lawan. Contoh dari jenis permainan ini yakni Arena Of Valor (AOV), Mobile Legends, dan lain-lain.

(https://esportsnesia.com/penting/apaitu-moba/).

Beberapa dampak positif dari game online adalah sebagai berikut: 1) dapat meningkatkan konsentrasi, 2) dapat meningkatkan kemampuan motoric setiap pemain, 3) dapat meningkatkan kemampuan berbahasa asing, 4) dapat meningkatkan pengetahuan tentang komputer, 5) dapat meningkatkan kemampuan bekerja sama, 6) dapat meningkatkan kecepatan mengetik, dan 7) dapat menurunkan tingkat stress.

Sedangkan dampak negatif dari game online adalah sebagai berikut: 1) dapat menimbulkan kecanduan yang berat, 2) dapat mendorong pemain untuk melakukan hal-hal yang negatif, 3) sering berbicara kasar dan kotor kepada orang lain, 4) dapat membuat kegiatan yang ada di dunia nyata terbengkalai, 5) dapat membuat pola makan serta istirahat berubah, 6) adanya pemborosan pada pemain game online, 7) dapat memunculkan gangguan pada segi kesehatan fisik (Surbakti, 2017: 32-36; Kustiawan dan Utomo, 2019: 11-16).

Menurut Kimberly Young, game online merupakan kegiatan yang dapat menguras emosi serta menghabiskan banyak waktu. Untuk membuat banyak waktu dalam bermain game online, para pecandu game online ini sering mengabaikan tidur, diet, latihan, melakukan hobi, dan bersosialisasi dengan lingkungan sekitarnya.

Tanda-tanda seseorang telah kecanduan bermain game online menurut Kimberly Young adalah sebagai berikut:

1. Keasyikan dengan permainan (Preoccupation with Gaming),
2. Berbohong atau menyembunyikan penggunaan game (Lying or Hiding Gaming Use),

3. Kehilangan minat pada kegiatan lain (Loss of Interest in Other Activities),

4. Adanya penarikan sosial (Social Withdrawal),

5. Adanya pembelaan diri dan kemarahan pada individu tersebut (Defensiveness and Anger),

6. Adanya penarikan secara psikologis (Psychological Withdrawal),

7. Menggunakan game sebagai pelarian (Using Gaming as an Escape), dan

8. Terus-menerus menggunakan game meskipun sudah tahu konsekuensinya (Contiued Use Despite Its Consequences (Young, :360-262).

Terdapat beberapa jenis kecanduan internet menurut Kimberly Young, diantaranya: 1) kecanduan situs porno (cyber-sexual addiction), 2) kecanduan berhubungan dalam dunia internet (cyberrelational addiction), 3) kecanduan yang berhubungan dengan net compulsion, 4) kecanduan informasi internet (information overload), dan 5) kecanduan komputer (computer addiction).

Demikianlah beberapa hal yang perlu difahami terkait dengan game online.

Adapun yang dimaksud dengan ketaatan beribadah adalah kepatuhan terhadap segala perintah serta laranganAllah untuk menunaikan segala kewajiban yang diperintahkan dan menjauhi larangan. Setiap manusia di bumi ini memiliki kewajiban yang paling utama yakni beribadah serta dalam melakukannya juga harus hanya semata- 
mata untuk patuh kepada Allah SWT. (Alim, 2006: 143). ${ }^{1}$

Kataatan beribadah merupakan sikap yang sangat penting yang harus dimiliki oleh manusia. Bagi orang ketaatan beribadah dapat mengurangi demensia. Orang-orang lansia yang memiliki ketaatan ibadah lebih terjaga dari terkena demensia (Rizal, 2018: 14)..Ketaatan beribadah juga dapat menumbuhkan kebahagiaan hidup. Syafarina et.al. (2017: 11) dalam penelitian mereka menunjukkan bahwa orang lansia orang memiliki ketaatan beribadah yang baik memiliki tingkat kebahagiaan yang lebih tinggi dari mereka yang tidak memiliki ketaatan ibadah yang baik. Selanjutnya, ketaatan beribadah dapat menumbuhkan kesehatan mental yang baik (Reza, 2015:114; Mahfud et.al., 2015: 35). Orang yang memiliki ketaatan ibadah yang baik lebih memiliki kesehatan mental yang baik sehingga ia mampu mengendalikan dan mengontrol dirinya untuk mewujudkan ketenangan dan kebahagiaan serta prestasi-prestasi hidup.

Ketaatan seseorang terhadap agamanya tidak bisa dilepaskan dari pemahamannya terhadap ajaran-ajaran agamanya (Aris, 2010: 76; Sari, 2018: 68). Orang memiliki pemahaman agama yang baik cenderung melakukan ketaatan beribadah meskipun intensitas beribadahnya berbeda-beda antara satu orang dengan yang lain termasuk dalam hal ini saat bermain game online. Meskipun bermain game online, namun kewajiban agama tetap diperhatikan. Penelitian Wijaya (2017) menunjukkan bahwa intensitas bermain game online memiliki hubungan yang negatif terhadap kedisiplinan shalat lima waktu pada siswa kelas VIII MTs Muhammadiyah Tawangsari Kabupaten Sukoharjo.

\footnotetext{
${ }^{1}$ Muhammad Alim, Pendidikan Agama Islam Upaya Pembentukan Pemikiran dan
}

\section{METODE}

Penelitian ini menggunakan pendekatan kuantitatif dengan jenis penelitian hubungan kausal yakni menguji ada/tidak adanya hubungan sebab dan akibat dari dua variabel.

Populasi dalam penelitian ini adalah seluruh mahasiswa aktif jurusan Pendidikan Agama Islam Universitas Muhammadiyah Malang yang berada di Angkatan 2017 dan 2018. Sedangkan untuk menentukan jumlah sampel yang dibutuhkan, peneliti menggunakan teknik slovin. Peneliti juga menggunakan purposive sampling untuk menentukan jumlah sampel penelitian, dengan menetapkan kriteria-kriteria sebagai berikut: 1) Mahasiswa aktif jurusan Pendidikan Agama Islam Universitas Muhammadiyah Malang angkatan 2017 dan 2018, 2) Aktif dalam bermain game online. Dengan menggunakan teknik slovin, maka terpilihlah 52 mahasiswa sebagai sampel.

Teknik pengumpulan data yang digunakan dalam penelitian ini adalah kuesioner yang bersifat tertutup dengan menggunakan pengukuran skala likert. Lembar kuesioner yang sudah diuji validitas dan realibilitasnya disebarkan melalui link Google Form. Data yang sudah terkumpul dianalisis dengan menggunakan rumus korelasi pearson product moment dengan aplikasi SPSS versi 16.

\section{HASIL}

\section{Intensitas Bermain Game Online.}

Berdasarkan pada hasil kuesioner yang telah disebar, dapat diketahui sebanyak 59,6\%. mahasiswa bermain game online melebihi jam yang sudah ditentukan. Game online yang paling banyak dimainkan adalah pada jenis MOBA yakni Mobile Legends, dengan hasil sebesar 40,4\%. Game online dilakukan mahasiswa untuk mengurangi

Kepribadian Muslim, (Bandung: PT. Remaja Rosdakarya, 2006), 143 
rasa bosan dan tidak menyenangkan yang dirasakan oleh mahasiswa, hal ini ditunjukkan dengan hasil persentase $40 \%$.

\section{Pengaruh Game Online terhadap Ketaatan Beribadah.}

Dari hasil yang diperoleh dari kuesioner diperoleh hasil mahasiswa yang bermain game online, $30 \%$ mementingkan kegiatan dan ibadahnya terlebih dahulu, namun $40 \%$ responden lebih mementingkan untuk bermain game online terlebih dahulu kemudian melaksanakan ibadah, sedangan sisanya $30 \%$ tidak menentu.

Dari analisis SPSS pengaruh game online terhadap ketaatan beribadah (dalam hal ini shalat) dapat dilihat pada table berikut:

\begin{tabular}{llcc} 
& Correlations & \multicolumn{3}{c}{$\begin{array}{c}\text { Intensitas } \\
\text { Bermain } \\
\text { Game } \\
\text { Online }\end{array}$} & $\begin{array}{c}\text { Ketaatan } \\
\text { Beribadah }\end{array}$ \\
\hline Intensitas & Pearson & 1 & -.206 \\
Bermain & Correlation & & .143 \\
Game online & Sig. (2-tailed) & & 52 \\
\hline Ketaatan & N & 52 & 1 \\
Beribadah & Coarson & -.206 & \\
& Sig. (2-tailed) & .143 & 52 \\
& N & 52 & \\
\hline
\end{tabular}

\section{PEMBAHASAN}

\section{Intensitas Bermain Game Online}

Dari paparan di atas, dapat diketahui bahwa mayoritas mahasiswa jurusan pendidikan agama Islam fakultas agama Islam UMM bermain game online melebihi jam yang sudah ditentukan. Mereka umumnya bermain game MOBA yakni Mobile Legends. Kegiatan ini mereka lakukan untuk mengurangi rasa bosan dan mencari hiburan atau hanya sebagai selingan saja.

\section{Pengaruh Game Online Terhadap Ketaatan Beribadah \\ Dari paparan hasil penelitian di} atas, dapat diketahui bahwa meskipun mereka intens bermain game online, namun mereka tidak meninggalkan kewajibannya menjalankan ibadah kepada Allah, meskipun mayoritas mereka masih mendahulukan bermain game online dari pada menjalankan shalat.

Dari uji korelasi pearson product moment didapatkan hasil $-0,206<0,279$ $\left(r_{\text {hitung }}<r_{\text {tabel }}\right)$. Dengan hasil $r_{\text {hitung }}$ yang negatif tersebut, dapat disimpulkan bahwa tidak ada hubungan yang berarti antara intensitas bermain game online terhadap ketaatan beribadah mahasiswa program studi Pendidikan Agama Islam Universitas Muhammadiyah Malang. Hal ini menguatkan hasil penelitian Wijaya (2017) yang menunjukkan korelasi negative antara intensitas bermain game online terhadap ketaatan beribadah. Namun demikian, melihat hasil kuesioner di atas bahwa ada kecenderungan bermain game online mengurangi kualitas ketaatan beragama. Hal ini ditunjukkan bahwa mayoritas mahasiswa lebih mementingkan meneruskan bermain game online dan mngakhirkan ibadahnya.

Dari sini juga dapat difahami bahwa pemahaman seseorang terhadap ajaran agamanya memberikan pengaruh terhadap ketaatan beragama. Mahasiswa jurusan pendidikan agama Islam yang memiliki pemahaman agama Islam yang baik cenderung tetap menjalankan ibadah meskipun memiliki intensitas yang tinggi dalam bermain game online. Hal ini sejalan dengan hasil penelitian Aris (2010) dan Sari (2018) yang menunjukkan bahwa pemahaman agama memiliki korelasi dengan ketaatan beribadah. 


\section{KESIMPULAN DAN SARAN Kesimpulan}

Berdasarkan hasil penelitian, dapat disimpulkan bahwa mayoritas mahasiswa di Jurusan Pendidikan Agama Islam di Universitas Muhammadiyah Malang $(59,6 \%)$ mahasiswa intens bermain game online. Hal itu dilakukan untuk menghilangkan kepenatan dan mengurangi hal-hal yang tidak menyenangkan.

Berdasarkan hasil analisis pearson product moment tentang pengaruh intensitas bermain game online dengan ketaan beribadah diperoleh hasil $-0,206<$ 0,279 ( $\left.\mathrm{r}_{\text {hitung }}<\mathrm{r}_{\text {tabel }}\right)$. Dengan demikian dapat disimpulkan bahwa tidak ada pengaruh yang berarti antara intensitas bermain game online terhadap ketaatan beribadah mahasiswa program studi Pendidikan Agama Islam Universitas Muhammadiyah Malang. Namun demikian, bermain game online dapat mengurangi kualitas ketaatan beribadah.

\section{Saran}

Berdasarkan kesimpulan yang diperoleh, maka dapat diberikan saran sebagai berikut:

1. Bagi orang tua, sebaiknya tetap harus mengontrol jam bermain game online pada anaknya. Hal ini diperlukan agar pelaksanaan ibadah sholat 5 waktu mereka tidak berantakan dan dapat dilaksanakan tepat waktu.

2. Bagi mahasiswa, perlu ditata kembali untuk pembagian waktu untuk bermain game online, agar saat waktu pelaksanaan sholat 5 waktu, tidak terbentur dengan waktu bermain.

\section{DAFTAR RUJUKAN}

Adams, Ernest. (2010). Fundamentals of Game Design. California: New Riders.
Alim, Muhammad. (2006). Pendidikan Agama Islam Upaya Pembentukan Pemikiran dan Kepribadian Muslim. Bandung: PT. Remaja Rosdakarya.

Darwis, M., Amri, K., \& Reymond, H. (2020). Dampak Dari Kecanduan Game Online Di Kalangan Remaja Usia. Ristekdik (Jurnal Bimbingan Dan Konseling), 5(2), 228-233.

Efektivitas, R. (2016). Efektivitas Pelaksanaan Ibadah Dalam Upaya Mencapai Kesehatan Mental. Psikis : Jurnal Psikologi Islami, 1(1), 105115.

Kustiawan, Andri Arif, Andy Widhiya Bayu Utomo. (2019). Jangan Suka Game online : Pengaruh Game online Dan Tindakan Pencegahan. Magetan: CV. AE Media Grafika

Mahfud, D., Mahmudah, \& Wihartati, W. (2015). Kesehatan Mental Mahasiswa Uin Walisongo. 35(1), 35-51.

Nisrinafatin. (2020). Pengaruh Game Online Terhadap Motivasi Belajar Siswa. Jurnal Edukasi Nonformal, 115-122.

Novrialdy, E. (2019). Kecanduan Game Online pada Remaja: Dampak dan Pencegahannya. Buletin Psikologi, 27(2),

148. https://doi.org/10.22146/buletinpsik ologi.47402

Novrialdy, E. (2019). Kecanduan Game Online pada Remaja: Dampak dan Pencegahannya. Buletin Psikologi, 27(2), 148. https://doi.org/10.22146/buletinpsik ologi.47402

Ondang, G. L., Mokalu, B. J., \& Goni, S. Y. V. I. (2020). Dampak Game Online Terhadap Motivasi Belajar Mahasiswa Jurusan Sosiologi Fispol Unsrat. Jurnal Holistik, 13(2), 1-15.

Ramadhani, Ardi. (2013, Maret). Hubungan Motif Bermain Game Online dengan Perilaku 
Agresivitas Remaja Awal (Studi Kasus di Warnet Zerowings, Kandela dan Mutant di Samarinda). eJournal Ilmu Komunikasi. Vol. 1, No. 1. 142143

Rizal, M.Abdur. (2018).Hubungan Ketaan Beribadah (Sholat) dengan Tingkatan Demensia pada Lansia di Kelurahan Bendan Kergon Kota Pekalongan. PENA MEDIKA. 14-27.

Sari, R. D. (2018). Pengaruh Pemahaman Agama Terhadap Perilaku Keagamaan Remaja Desa Ngestirahayu Kecamatan Punggur Kabupaten Lampung Tengah. Skripsi. Jurusan PAI-IAIN Metro Lampung

Sudarsono. (2018). Pendidikan Ibadah Perspektif al-Quran dan Hadits. CENDIKIA: Jurnal Studi Keislaman. 4 (1), 54-65

Surbakti, Krista. (2017, April). Pengaruh Game online Terhadap Remaja. Jurnal Curere. Vol. 01, No. 01. 30-35

Syarafina, Zahra Kautsar;Kholifah, Siti Nur;Heryanto, Bambang;Fadillah, N. (2017). Hubungan Ketaatan Beribadah Dengan Kebahagiaan Lansia. Jurnal Keperawatan, 10(1), $11-16$.

http://journal.poltekkesdepkessby.ac.id/index.php/KEP/article/vie $\mathrm{w} / 766$

Tiyono, Aris. (2010).Pengaruh Pemahaman PAI terhadap Pengamalan Ibadah Siswa ( Studi Kasus Di SMP Islam Ngadirejo Temanggung). Skripsi. Program Studi Pendidikan Agama Islam Sekolah Tinggi Agama Islam Negeri ( STAIN ) Salatiga.

Utami, T. W., \& Hodikoh, A. (2020). Kecanduan Game Online Berhubungan Dengan Penyesuaian Sosial Pada Remaja. Jurnal Keperawatan, 12(1), 17-22.
Young, K. (2009, September). Understanding Online Gaming Addiction and Treatment Issues for Adolescents. The American Journal of Family Therapy, Vol. 37, Issue 5, 355-366

Young, K., dkk. (2000, Tanpa Bulan). Cyber-Disorders: The Mental Health Concern for the New Millennium. CyberPsychology \& Behavior, Vol.3, No.5, 475-479

Yusuf, A., Krisnana, I., \& Ibrahim, A. (2019). Hubungan Kecanduan Game Online Dengan Komunikasi Interpersonal Dan Interaksi Sosial Remaja. Psychiatry Nursing Journal (Jurnal Keperawatan Jiwa), 1(2), 71. https://doi.org/10.20473/pnj.v1i2.13 591

https://www.it-jurnal.com/pengertianinternet/ Diakses pada tanggal 31 Juli 2020

https://esportsnesia.com/penting/apaitu-moba/. Diakses pada tanggal 13 April 2020

http://id.wikipedia.org/wiki/Permaina n_daring. Diakses pada tanggal 10 Maret 2020

https://kumparan.com/kumparantech/ di-indonesia-mobile-legendsdimainkan-8-juta-penggunaaktif/full. diakses pada tanggal 5 Oktober 2020 